\title{
A ESCRITA GAMIFICADA DE FANFICTIONS \\ COM O APOIO DE TECNOLOGIAS DIGITAIS \\ EM UM CLUBE DE INGLÊS
}

\author{
THE GAMIFIED WRITING OF FANFICTIONS \\ WITH DIGITAL TECHNOLOGIES \\ IN AN ENGLISH CLUB
}

\author{
Adriana Fischer ${ }^{*}$ \\ Camila Grimes** \\ Mariana Aparecida Vicentini ${ }^{* * *}$
}

\section{RESUMO}

Este estudo tem por objetivo compreender relações entre práticas de letramento escolar e a escrita gamificada de fanfictions com o apoio das Tecnologias Digitais (TD). As fanfictions podem ser definidas como ficções escritas por fãs com base em um produto original e têm se popularizado com a disseminação da internet, especialmente entre adolescentes em idade escolar. A justificativa para o desenvolvimento de práticas de leitura e escrita com o gênero fanfiction, neste estudo, ampara-se em uma perspectiva sociocultural dos estudos dos letramentos, em que o foco na aprendizagem de um gênero não está na assimilação de sua estrutura unicamente, mas nos modos como a aprendizagem de um gênero oportuniza conhecimentos de formas particulares. As mediações em torno das atividades com fanfictions aconteceram no contexto de um Clube de Inglês, com cinco sujeitos. Os dados foram gerados com base em enunciados desses sujeitos na plataforma de gamificação Classcraft, a partir da fanfiction escrita durante as aulas do Clube e de um grupo focal realizado com esses sujeitos. Para proceder com as análises, construímos uma linha do tempo apresentando a relação dos sujeitos com as fanfictions antes das atividades feitas no Clube, as aproximações, interações e posicionamentos durante o percurso de escrita e suas percepções sobre como foi o trabalho com o gênero a partir de diferentes abordagens metodológicas, posteriormente à prática de escrita da fanfiction. Os resultados apontam, principalmente, para a inserção desses sujeitos, na condição de insiders, em diferentes práticas de letramentos que envolvem a leitura e a escrita do gênero fanfiction, mediadas pelos usos de TD. Ainda, há indícios de que a gamificação permitiu aos sujeitos evidenciarem formas singulares de se posicionar em

\footnotetext{
* Universidade Regional de Blumenau, FURB, Blumenau, SC, Brasil. adrfischer@furb.br Orcid: https://orcid.org/0000-0001-9787-2814

** Universidade Regional de Blumenau, FURB, Blumenau, SC, Brasil. professora.camilagrimes@ gmail.com

Orcid: https://orcid.org/0000-0003-0105-4046

*** Universidade Regional de Blumenau, FURB, Blumenau, SC, Brasil. amarivicentini@gmail.com Orcid: https://orcid.org/0000-0001-6256-2904
} 
relação à leitura, à escrita e diferentes formas de ser, agir e elaborar sentidos no contexto escolar.

Palavras-chave: fanfiction; práticas de letramentos; gamificação.

\section{ABSTRACT}

This study aims to understand relationships between school literacy practices and the gamified writing of fanfictions with the support of Digital Technologies (DT). The fanfictions are fictional stories written by fans based on an original product. They have become popular with the spread of the internet, especially among school-age teens. The justification for the development of reading and writing practices with the genre fanfiction, in this study, is based on a socio-cultural perspective of the literacy studies, in which the focus on learning a genre is not just in the assimilation of its structure, but in the ways in which the learning of a genre affords knowledge in particular ways. Mediations surrounding fanfictions took place in the context of an English Club with five subjects. The data come from statements of these subjects on the Classcraft gamification platform, from the fanfiction written during the Club classes and from a focus group performed with these subjects. In order to proceed with the analyzes, we constructed a timeline showing the relationship of the subjects with the fanfictions before the activities developed in the Club, the approximations, interactions and positioning during their writing trajectory and their perceptions about how the activities involving the genre from the use of different methodological approaches, after the writing practice of fanfiction. The results point mainly to the insertion of these subjects, as insiders, in different literacy practices involving the reading and writing of the genre fanfiction, mediated by the uses of DT. Furthermore, there are indications that the gamification allowed the subjects to evidence singular ways of positioning themselves in relation to reading, writing and different ways of being, acting and creating meanings in the school context.

Keywords: fanfiction; literacy practices; gamification.

\section{ENFOQUES INICIAIS}

Investigações acerca de qual seria a abordagem adequada envolvendo o ensino ou a aprendizagem de uma língua estrangeira têm despertado o interesse de pesquisadores, " [...] com ênfase especial na segunda metade do século XX" (LEFFA et al., 2017, p. 114), por conta do surgimento das Tecnologias Digitais (TD). Para o desenvolvimento deste estudo, partimos do pressuposto de que não existe um consenso metodológico para o ensino de uma segunda língua, mas que, a partir de um olhar de perspectiva etnográfica (LILLIS, 2008; FRITZEN, 2012) às práticas de letramentos dos que buscam aprender uma segunda língua, é possível criar condições que possibilitem a inserção de sujeitos em práticas de letramentos significativas. 
Foi a partir de práticas desenvolvidas em um Clube de Inglês ${ }^{1}$, em torno do gênero fanfiction, que traçamos o objetivo do presente trabalho: compreender relações entre práticas de letramento escolar e a escrita gamificada de fanfictions com o apoio de Tecnologias Digitais.

Os enfoques apresentados neste artigo integram estudos que ocorrem no contexto de um Programa de Pós-Graduação em Educação de uma universidade localizada no interior de Santa Catarina.

A proposta se ampara teoricamente em uma perspectiva dos Novos Estudos dos Letramentos (NEL), que compreendem os letramentos como práticas flexíveis de leitura, oralidade e escrita, de cunho social e, portanto, ideológicas e sóciohistoricamente situadas. Acrescentamos, aqui, que o termo "novos" não remete, neste estudo, unicamente ao uso das TD como ferramentas, as quais podem, de forma muito simplificada, apontar para inovações em âmbito escolar. O diferencial reside em singulares encaminhamentos de ensino e efetivas produções escritas pelos estudantes, nas interações com as TD, sem descartar problematizações que emergem em práticas de letramentos com TD.

Nessa direção, as práticas de letramentos abordadas no decorrer de nosso trabalho envolvem: a) o uso de TD concebidas, aqui, como mecanismos que ressignificam e refratam (BAKHTIN, 2011) os letramentos, peças-chave dos contextos educacionais contemporâneos, por oferecerem uma diversidade de possibilidades para as mudanças nas interações em práticas desenvolvidas no contexto escolar (LEA; HAMILTON; GOURLAY, 2014); b) a gamificação, definida por Deterding et al. (2011) como o uso de características dos jogos em contexto não jogo, uma vez que práticas de letramentos são compreendidas como sociais, vinculadas a formas de pensar, agir, valorizar e (re)significar identidades; e c) a concepção de linguagem adotada nesta pesquisa é a dialógica (BAKHTIN, 2011), sem desconsiderar conflitos nos processos de ensino e escrita das fanfictions.

Destaca-se que a justificativa para práticas de leitura e escrita com o gênero fanfiction se ampara em Street, Lea e Lillis (2015) ao afirmarem que, em uma perspectiva sociocultural dos estudos dos letramentos, o foco não está na assimilação da estrutura ou nas particularidades do gênero unicamente, mas em revelar como o ensino de um gênero cria conhecimento de formas particulares, ou seja, o ensino de um gênero é capaz de oportunizar, em um determinado sujeito ou comunidade de prática (WENGER, 2004), a construção de sentidos (GEE, 2001).

1.O Clube de Inglês é uma atividade extracurricular oferecida aos estudantes de um primeiro ano do Ensino Médio da escola em que o estudo foi desenvolvido. Demais informações sobre o clube estão dispostas na seção metodológica. 
No caso das atividades relacionadas à fanfiction, no Clube de Inglês, esses sentidos se relacionam à percepção dos sujeitos em torno de outra abordagem facilitadora da aprendizagem da língua inglesa, que não a de caráter normativo. Ainda, os sentidos desses sujeitos se constroem a partir da relação entre suas experiências prévias em torno das fanfictions e os movimentos com esse gênero durante as aulas do Clube de Inglês.

Por fim, almejando contribuir com essa discussão, este trabalho está estruturado em mais quatro seções. Na seção seguinte, apresentamos as articulações teóricas que fundamentam este estudo. A seção três descreve o percurso metodológico seguido para mediar práticas de letramentos no Clube de Inglês. Na quatro, analisamos os dados com apoio da teoria dos NEL e, na seção cinco, tecemos considerações finais sobre a pesquisa e seus resultados.

\section{OLHARES AO GÊNERO FANFICTION}

Antes de iniciarmos as principais discussões acerca da fanfiction como um gênero do discurso que está emergindo na esfera escolar e que acreditamos possibilitar a inserção de estudantes em práticas de letramentos significativas, consideramos relevante destacar que, neste estudo, concebemos os gêneros do discurso, pela já conhecida conceituação do Círculo de Bakhtin, como "tipos relativamente estáveis de enunciados" (BAKHTIN, 2011, p. 262), ou seja, através de enunciados individuais, que emergem durante percursos de interação e que se movimentam em direção a regularidades surge o gênero e essa relativa estabilização acontece por meio de seu uso em interações concretas semelhantes, que se dão nas diferentes esferas da atividade humana. Dito de outro modo, onde surge uma nova situação social de interação, seja oral ou escrita, surge também um novo gênero (BAKHTIN, 2011). Isso significa dizer que, uma vez construídos, os gêneros do discurso podem se alterar e se complexificar em virtude das especificidades das interações sociais.

O gênero fanfiction e as práticas de letramentos (STREET, 2003; BARTON; HAMILTON, 2000) que com ela se relacionam surgiram no interior do fandom, ou seja, "no interior de um movimento de consumidores de produtos criados pela indústria do entretenimento e veiculados pelos meios de comunicação de massa" (VARGAS, 2015, p. 11). Segundo a autora, etimologicamente, a palavra seria "a fusão dos termos ingleses fan e kingdom, configurando assim o reino, domínio ou espaço dos fãs" (VARGAS, 2015, p. 11). 
Popularmente conhecida como fanfic, abreviação do termo em inglês fanfiction, ou seja, ficção criada por fãs, ocupa-se de contos escritos por terceiros. Os autores de fanfictions, popularmente conhecidos como ficwriters, e os leitores, conhecidos como ficreaders, dedicam-se a escrevê-las e lê-las por conta da afinidade que possuem com a obra original. Nesse sentido, não lhes basta consumir o material original que lhes é disponibilizado, passando a haver a necessidade de interagir, interferir naquele universo ficcional e, no caso dos autores, de deixar sua marca de autoria. Deste modo, os fandoms passam a interagir com um produto, por meio da produção escrita, lendo, criando e recriando histórias fictícias, realizando interações colaborativas e frequentando diversos ambientes de forma simultânea (BARBOZA, 2016).

Cabe destacar que a disseminação das TD tornou-se especialmente importante para a difusão de trabalhos realizados por esses fãs a partir de originais e na criação de comunidades de prática (WENGER, 2004) em torno do universo fanficcional. Barboza (2016) explica que os fãs teriam sido os primeiros a adotar as TD com o fim de expandir o universo interativo de suas comunidades e, dessa forma, seu modo de proceder em relação aos produtos culturais difundidos nos meios de comunicação de massa constitui uma referência na relação entre as fanfictions e a indústria do entretenimento.

Em meio às discussões levantadas até o momento, cabe destacar as hibridizações presentes nas relações estabelecidas nas práticas de leitura e escrita de fanfictions em uma perspectiva sociocultural, pois, segundo Buzato (2009), essas relações incluem, além das mídias ou dispositivos digitais e das práticas sociais, os gêneros vinculados às diferentes atividades sociais, culturais e localizações geográficas e as atitudes dos sujeitos perante o conteúdo em questão, neste caso, nas práticas de letramentos com fanfictions. Todos esses elementos, se analisados em conjunto, podem indicar de que formas o gênero e as práticas de letramentos sobre e em torno dele se constituem e são constituídos pelas relações sociais que possibilitam.

A questão dos gêneros literários no universo das fanfictions preserva elementos em comum com o modo como são compreendidos no universo escolar, mas também apresentam características próprias. Os estudos de Barboza (2016) apontam para o surgimento das fanfictions como uma forma narrativa intermediária, entre short story (conto) e novel (romance/novela), tendo sua tipologia definida pelos próprios fandoms. Sua nomenclatura e organização são atualizadas em cada website, de acordo com o entendimento daqueles que o gerenciam e de acordo com as necessidades do fandom que o frequenta. Alguns gêneros chegaram a ser criados para que fosse possível classificar algumas das obras produzidas pela imaginação fértil dos autores, e são encontrados apenas na prática da fanfiction, conforme pode ser observado na Figura 1: 


\begin{tabular}{|c|c|c|c|}
\hline Forma & $\begin{array}{l}\text { Especificação/ou } \\
\text { tra denominação }\end{array}$ & Extensão aproximada & $\begin{array}{l}\text { Possiveis analogias com a } \\
\text { literatura convencional }\end{array}$ \\
\hline \multicolumn{4}{|c|}{ Long Fictions } \\
\hline \multirow[t]{2}{*}{ Longfics } & longfics & Acima de 20 capitulos & \multirow{2}{*}{$\begin{array}{c}\text { Romances / novelas médias } \\
\text { (novelettes / novellas) ou } \\
\text { longas }\end{array}$} \\
\hline & sagas & Acima de 50 capitulos & \\
\hline \multicolumn{4}{|c|}{ Short Fictions } \\
\hline Shortfics & Shortfics & Até 20 capítulos & $\begin{array}{l}\text { Contos, novelas curtas e/ou } \\
\text { médias (novelettes/novellas) }\end{array}$ \\
\hline One-Shots & Onse-shots & Um capítulo (médio / curto) & Contos curtos e/ou médios \\
\hline \multicolumn{4}{|c|}{ Short-Short Fictions } \\
\hline Ficlets & Flashfics/quickfics & $\begin{array}{l}\text { Até três páginas; ou acima } \\
\text { de } 500 \text { e até } 2000 \text { palavras }\end{array}$ & Contos curtos \\
\hline \multirow{6}{*}{ Drabbles } & half-drabble & 50 palavras & \multirow{6}{*}{$\begin{array}{l}\text { Contos muito curtos } \\
\text { (micronarrativas) }\end{array}$} \\
\hline & drabble & 100 palavras & \\
\hline & Double-drabble & 200 palavras & \\
\hline & Triple-drabble & 300 palavras & \\
\hline & Quad-drabble & 400 palavras & \\
\hline & $5 x$ drabble & 500 palavras & \\
\hline
\end{tabular}

Figura 1. Classificação das fanfictions.

Fonte: Barboza (2016).

A partir das discussões acerca da organização das fanfiction, como indicado na Figura 1, pode-se observar questões de relações de poder que permeiam essa esfera. Dentro da esfera da cultura popular, os fãs são os verdadeiros especialistas que constituem uma elite educacional concorrente, ainda que sem reconhecimento oficial ou poder social (BARBOZA, 2016). Nessa proporção, explica a autora, o fã seria um especialista, no sentido de um conhecedor em profundidade da cultura popular a que se dedica. No universo dos fandoms, grupos de fãs poderão compartilhar uma série de valores e conhecimentos presumidos, talvez desconhecidos, por membros de outro fandom, que não necessariamente compartilham os mesmos valores sobre o original em questão.

$\mathrm{Na}$ seção seguinte, delimitamos as principais considerações acerca de como, partindo da interação com as fanfictions, os estudantes de um Clube de Inglês puderam, também com apoio de experiências como leitores do gênero, vivenciar a prática de escrita de uma fanfiction com o apoio das TD e da gamificação, como fomento à aprendizagem da língua inglesa em uma perspectiva sociocultural dos estudos dos letramentos. 


\section{A GAMIFICAÇÃO E AS TD COMO APOIO A PRÁTICAS COLABORATIVAS DE ESCRITA DE FANFICTIONS NO CLUBE DE INGLÊS}

A prática de escrita da fanfiction ocorreu em uma escola localizada no interior de Santa Catarina, durante as atividades do Clube de Inglês, com cinco sujeitos, conforme segue:
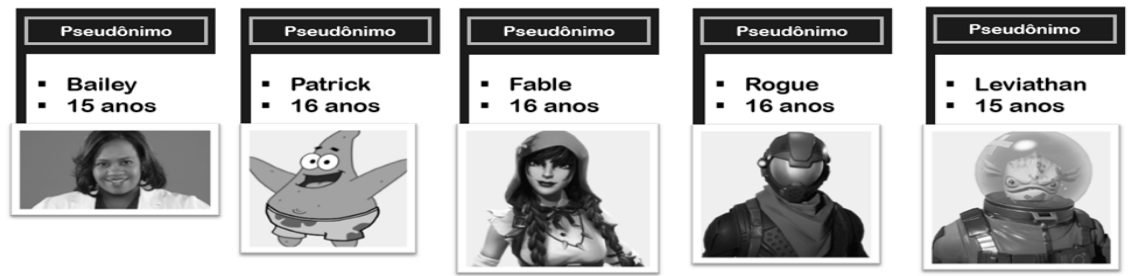

Figura 2. Sujeitos da pesquisa² .

Fonte: elaborado pelas autoras (2019).

O Clube de Inglês é dividido entre os níveis Básico (Intro), Pré-intermediário (1A) e Intermediário (2A), sendo focado, neste estudo, o trabalho com o nível Intermediário. As aulas do Clube de Inglês, inicialmente, eram realizadas na própria sala de aula do Ensino Médio, no contraturno, a partir de uma apostila com foco no desenvolvimento das quatro habilidades da língua: ler, falar, ouvir e escrever. Por conta da abordagem normativa praticada durante as aulas, os estudantes pouco se engajavam nas aulas do Clube. A representação dessa abordagem de cunho normativo se manifestava dentro do Clube, por meio de exercícios estruturados e descontextualizados das práticas sociais que os estudantes desenvolviam fora da escola, a exemplo de uma atividade de redação em que deveriam escrever um texto com o tema "Sharing Economy" ${ }^{\text {", }}$ sem que o material tivesse abordado qualquer contextualização a respeito do tema previamente. Ademais, as unidades da apostila eram divididas em seções com explicação sobre conteúdos gramaticais, compreensão auditiva, com questões para assinalar ou preencher lacunas, e um exercício para estímulo de interação oral a cada unidade, com cerca de dois questionamentos para a interação entre a turma. Apesar disso, os estudantes conseguiam interagir durante a aula usando, praticamente, apenas a língua inglesa, mesmo afirmando nunca terem participado de aulas em escolas de idiomas e interagindo com o inglês apenas nas

2.Os pseudônimos foram escolhidos pelos sujeitos durante as aulas do Clube de Inglês para usos nas aulas gamificadas. Durante as aulas os sujeitos eram referidos apenas pelo uso dos pseudônimos.

3. Economia compartilhada 
aulas das escolas regulares, bem como afirmando terem adquirido aquele nível de proficiência por conta de suas interações em jogos online.

As problemáticas apresentadas até o momento em relação à participação dos sujeitos nas atividades do Clube e seus depoimentos acerca da forma como aprenderam o inglês fomentaram a possibilidade de desenvolver novos movimentos dentro do Clube, por meio da gamificação, considerando o contato dos estudantes com jogos online.

A gamificação se constitui na utilização de princípios de jogos ${ }^{4}$ em cenários não jogo, criando espaços de aprendizagem ${ }^{5}$ mediados pelo desafio, pelo prazer e entretenimento. Abrange, ainda, a utilização desses princípios para a resolução de problemas e para a motivação e o engajamento de um determinado público. Isso não significa, necessariamente, a participação em um jogo, mas a utilização de elementos para reproduzir os mesmos benefícios alcançados com o ato de jogar (DETERDING, 2011; VIANNA et al., 2013).

Para a gamificação da prática de letramentos com fanfictions, optou-se pelo uso da plataforma Classcraft, que corresponde a uma plataforma online para criação e gamificação de atividades e que simula um jogo de role-playing (RPG) online gratuito que permite aos professores e aos estudantes jogarem juntos na sala de aula. $\mathrm{O}$ Classcraft utiliza muitas das convenções tradicionalmente encontradas nos jogos de hoje, como subir de nível, trabalhar em equipe e ganhar poderes que tenham consequências do mundo real.

A plataforma Classcraft funciona como um sistema de autoria aberto para a elaboração de Recursos Educacionais Abertos (REA), que podem ser utilizados e compartilhados tanto entre professores que atuam em diferentes contextos, quanto entre professores e estudantes durante as aulas. No Classcraft, é necessário que se faça um cadastro e o login como estudante ou professor. No perfil salvo como professor, é possível acessar as atividades elaboradas, acompanhar a pontuação dos estudantes e criar as próprias aulas, denominadas de missões. Já no perfil salvo como estudante, é possível acompanhar o seguimento das atividades gamificadas feitas por ele, com a pontuação, as equipes etc. Todas as atividades do Classcraft são gamificadas, conferindo às atividades elaboradas características de games: pontuação, ranking de classificação, montagem e escolha de avatar, avanço de fases, narrativas, trabalho em equipe etc. Após o login na plataforma, os estudantes podem escolher entre os avatares Mago, Guerreiro e Curandeiro e, em cada equipe, passam a ter

4. No contexto deste estudo nos referimos a jogos na modalidade multiplayer online.

5.Concebidos nesta pesquisa como distintos cenários escolares e não escolares que potencializam o desenvolvimento de habilidades cognitivas, habilidades sociais e habilidades motoras. 
níveis e as suas colocações, bem como conquistas e medalhas, que também são apresentadas. Todos esses elementos fizeram parte da prática de letramentos com fanfictions.

As pontuações dos estudantes são divididas em Health Points (HP), Action Points $(A P)$, Experience Points (XP), Golden Points (GP) e Power Points (PP), conforme destacado na Figura 3.

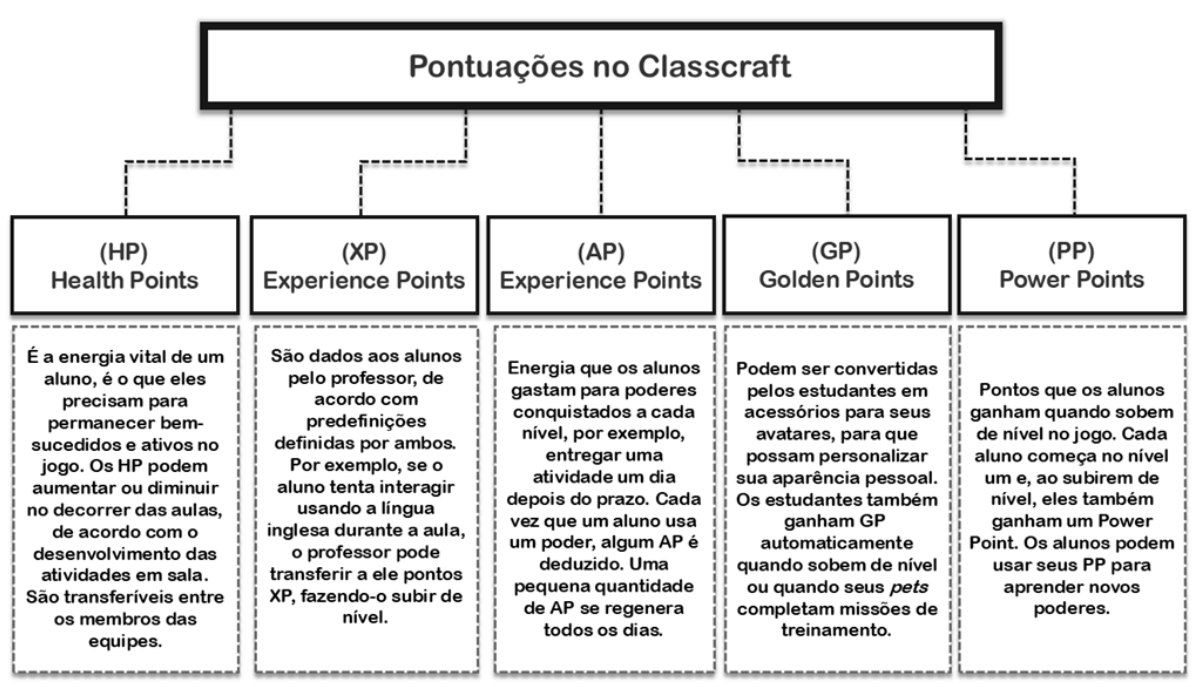

Figura 3. Pontuações no Classcraft.

Fonte: elaborado pelas autoras (2019).

As aulas que envolveram a prática de letramentos com fanfictions tiveram como base para gamificação, além dos elementos da plataforma Classcraft descritos até o momento, os princípios dos bons jogos de Gee (2005): sentidos contextualizados, interação e produção.

As interações dos sujeitos com as fanfictions e com as TD fora do contexto escolar indicam que o trabalho com esse gênero no Clube de Inglês pode resultar na construção de sentidos contextualizados dentro dessa prática de letramentos, principalmente pelo fato de, a partir da fanfiction, os sujeitos terem a possibilidade de confrontar o uso da linguagem informal com a norma padrão do inglês.

O princípio da interação, no caso deste artigo, envolveu o constante trabalho com as TD e com os demais integrantes da equipe. É possível que surja a falsa impressão de que outros métodos de aprendizagem utilizados anteriormente à gamificação, no Clube de Inglês, não propiciavam a interação entre sujeitos. Para 
esclarecer esse possível desentendimento, destaca-se que como nos games há a constante interação entre diversos sujeitos, buscou-se privilegiar esse tipo de interação intrapessoal, mas com a noção de que interações interpessoais também ocorreram e que são relevantes para o percurso de aprendizagem dos sujeitos.

O princípio da produção (GEE, 2005) se refere ao fato de que os estudantes tiveram a possibilidade de construir, coletivamente, o currículo para um determinado período de estudos, pois a proposta de escrita de uma fanfiction partiu dos próprios sujeitos. Somado a isso, os critérios que nortearam as interações entre os integrantes do Clube de Inglês e as etapas que se estenderam da seleção do gênero à produção final da fanfiction foram negociados entre a professora e os estudantes. Os critérios para o percurso de estudos sobre o gênero fanfiction aparecem demonstrados na figura 4 :

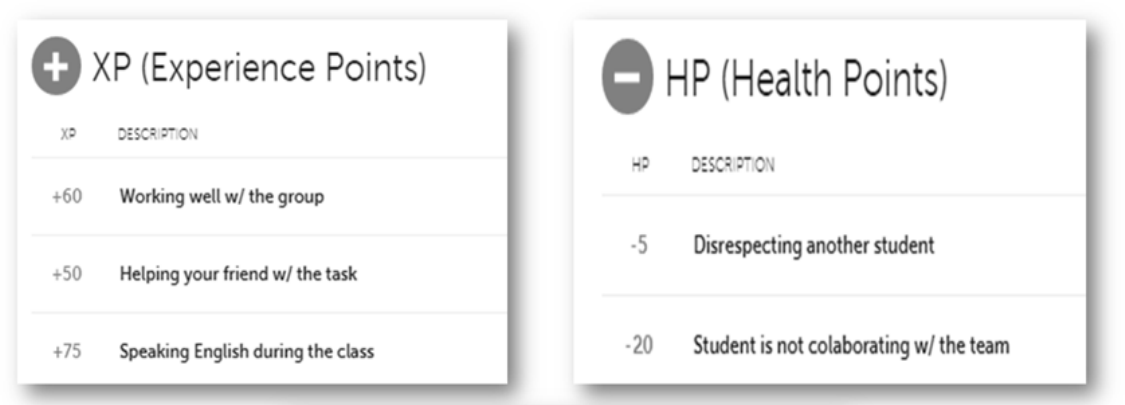

GP GP (Gold Pieces)

GP DEscrotion

+50 Attention during the lesson

$+50 \quad$ Being organized

Figura 4. Regras para elaboração da Fanfiction ${ }^{6}$

Fonte: elaborado pelas autoras (2019).

Como forma de dar início à prática da escrita da fanfiction, considerando que os sujeitos interagiram com esses textos por meio da leitura, sugeriu-se que realizassem uma busca acerca do gênero. Cada um deveria realizar a leitura de uma fanfiction em inglês, atendo-se não apenas à sua estrutura composicional, mas também a outros elementos como formas de se obter acesso e de divulgar esses textos.

6. Trabalhar bem com a equipe, ajudar um colega durante a atividade, falar inglês durante a atividade; desrespeitar outro colega, não colaborar com a equipe; atenção durante a atividade; organização. 
$\mathrm{Na}$ aula seguinte, os estudantes prepararam uma roda de conversa ${ }^{7}$ acerca de suas buscas, discorrendo sobre o que conheciam do gênero, seu histórico e formas de interação com as fanfictions, possibilitando a todos os integrantes da equipe a interação com o gênero e algumas de suas particularidades.

Posteriormente às discussões levantadas pelos estudantes acerca do gênero, foi solicitada a produção escrita de uma fanfiction por esses sujeitos, em língua inglesa e com livre apoio das TD disponíveis em sala para consultas e pesquisas. Destaca-se que os sujeitos tiveram cerca de uma hora para o desenvolvimento dessa atividade. $\mathrm{Na}$ Figura 5, estão dispostas as orientações dadas aos estudantes pelo Classcraft para o desenvolvimento da atividade.

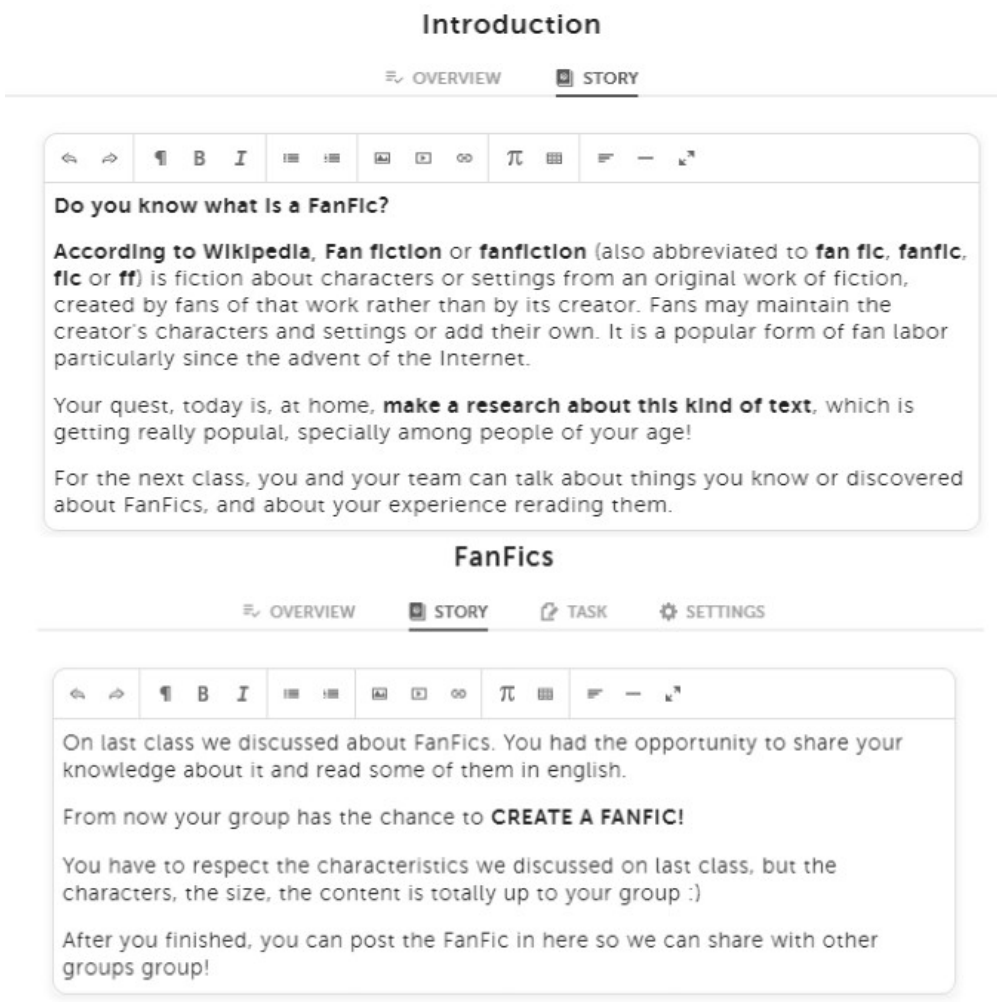

\section{Figura 5. Orientações no Classcraft para a escrita da fanfiction ${ }^{8}$. Fonte: elaborado pelas autoras (2018).}

7. Os estudantes não se sentiram confortáveis em autorizar a gravação da discussão e, portanto, esta não fará parte dos dados de análise deste estudo.

8. De acordo com a Wikipédia Fan fiction ou fanfiction (também abreviada como fan fic, fanfic, fic ou ff) é uma ficção sobre personagens ou características a partir de uma obra original criada pelos fãs dessa obra. Os fãs podem manter os personagens ou características do trabalho original ou podem 
Na seção seguinte, discutimos os dados que emergiram para análise a partir da plataforma Classcraft ${ }^{9}$, da fanfiction escrita pelos sujeitos e de um grupo focal realizado com os sujeitos ao final do semestre do Clube de Inglês. A seleção dos dados para a análise se deu por meio da observação de regularidades que deles emergiram. Ao passo em que foram transcritos os diálogos entre os sujeitos, durante o grupo focal, seus depoimentos na plataforma Classcraft foram agrupados a esse documento, para facilitar o confronto de informações. Posteriormente, foi feita a análise da fanfiction, em busca de relações entre os enunciados dos sujeitos, advindos do grupo focal, com a atividade produzida. As principais regularidades que emergiram a partir da triangulação desses dados foram: características das práticas de letramentos com fanfictions em contexto extraescolar, preferências de usos do inglês quando relacionado às trajetórias desses sujeitos, valoração às práticas de letramentos com TD, valoração a trabalhos colaborativos em detrimento de avaliações individuais.

\section{OS OLHARES SOBRE AS PRÁTICAS DE LETRAMENTOS COM FANFICTION NO CLUBE DE INGLÊS}

Como forma de dar início às análises, destacamos nosso posicionamento pelo ensino de inglês sob uma perspectiva sociocultural dos estudos dos letramentos, em que a leitura e a escrita são concebidas, conforme Zavala (2010, p. 73) "como sistemas simbólicos enraizados na prática social, inseparáveis de valores sociais e culturais, e não como habilidades descontextualizadas e neutras". Nessa perspectiva, o letramento sempre se desenvolve a partir de aprendizagens culturais e se adquire como parte da identidade das pessoas (GEE, 2000). Pensar os letramentos, dessa forma, significa considerar que a escola é um espaço plural que abarca múltiplas

criar seus próprios. É um trabalho bastante particular realizado por fãs e tem se popularizado especialmente com o advento da internet.

Sua missão hoje é a de, em casa, fazer uma pesquisa sobre esse tipo de texto que tem se popularizado, especialmente entre pessoas de sua idade.

Após a pesquisa, você e seu time podem compartilhar o que sabem e o que descobriram sobre as fanfictions, além de comentarem sobre sua experiência interagindo com fanfictions por meio da leitura. $\mathrm{Na}$ última aula nós discutimos sobre fanfictions. Você teve a oportunidade de compartilhar seus conhecimentos sobre o gênero e de ler uma fanfiction em língua inglesa.

A partir de agora, seu time tem a chance de escrever uma fanfic.

Você deve considerar as características sobre o gênero discutidas na última aula, mas os personagens, a extensão do texto, os conteúdos são responsabilidade do seu grupo.

Após terminar, você pode postar a fanfiction aqui (no Classcraft) para podermos compartilhá-la com outros membros do clube de inglês.

9. Esses dados são advindos de respostas dos estudantes quando questionados, por meio da ferramenta de bate-papo, no Classcraft, acerca de suas formas de interação com as fanfictions. 
epistemologias, identidades e relações de poder e que, portanto, as práticas de letramentos ali oportunizadas não devem ocorrer de forma verticalizada, como algo imposto aos estudantes, mas com comprometimento e colaboração, permitindolhes a criação de sentidos sobre o novo, a partir daquilo que já conhecem.

Tendo em vista que o impulso para o desenvolvimento deste estudo teve origem a partir da percepção de que os sujeitos desta pesquisa se mostravam extremamente desmotivados durante o percurso de aprendizagem da língua inglesa, especialmente por conta da abordagem adotada em sala de aula, destacamos dados advindos de uma pesquisa desenvolvida por Leffa (2007), acerca da autoexclusão de estudantes, no Brasil, quanto à aprendizagem de línguas estrangeiras. Assim como na visão do autor, a autoexclusão refere-se ao ato de incutir "no sujeito o desejo de se excluir de um determinado grupo e dá-se a ele a ilusão de que a escolha partiu de dentro dele" (LEFFA, 2007, p. 2), acreditamos que abordagens de caráter unicamente normativo e que não se relacionam com o contexto extraescolar dos estudantes, especialmente quanto à aprendizagem de inglês, podem promover nesses sujeitos a sensação de que não são aptos a aprender o idioma, ou o desejo de não aprendê-lo, quando, na verdade, segundo Vigostky (1896-1934a), a aprendizagem não depende de características biológicas de um sujeito, mas de interações dialógicas que ocorrem em diferentes contextos em que esses sujeitos estão inseridos, como é o caso da escola. Entre os principais fatores que promovem a exclusão, segundo o autor, estão: a) a escola como reprodutora dos valores da classe dominante; b) a universalização do ensino nas décadas de 1960 e 1970, em que as escolas foram divididas entre instituições para classes privilegiadas e não privilegiadas; e c) falta de qualificação dos professores. Todos esses fatores afetam o estudante, em geral, mas podem ser ainda mais contundentes, pois ao tentar estudar uma língua estrangeira, aspectos ideológicos podem torna-lo mais vulnerável ao processo de autoexclusão.

Para que mudanças possam ocorrer no contexto educacional, acreditamos ser necessário um deslocamento de determinadas ideologias, especialmente da que estipula "o que conta como letramento" (STREET; LEA posicionando de forma a poder ouvir e observar o que as pessoas estão realmente fazendo com a leitura, a escrita e a oralidade em práticas de letramentos.

A fim de atender ao objetivo deste estudo, de compreender relações entre práticas de letramento escolar e a escrita gamificada de fanfictions com o apoio de TD, problematizamos, a partir de agora, algumas questões que vão, desde a forma como os sujeitos deste estudo interagem com o gênero fanfiction em práticas de leitura fora da escola, até suas percepções acerca de como compreendem a prática de escrita 
desse gênero no Clube de Inglês, oportunizando discussões para pesquisas em torno da escrita de textos, pertencentes a um gênero como a fanfiction, circulante na internet, e que entra em sala de aula, para o ensino de línguas e para a educação em geral. Em relação às práticas de leitura, Patrick cita que:

[1] Eu não sou muito de ler livros, mas eu acho ler importante, então no tempo que eu não leio livros eu leio fanfic ${ }^{10}$. Então, eu não acho legal a gente ficar só no instagram e facebook, então eu procuro ler algo, e na fanfic é legal pq ${ }^{11}$ eu já descobri muitas coisas, muitas palavras, muitos acontecimentos da vida, coisas importantes, do porquê aquilo aconteceu, pq eu lia as fanfics (Patrick $;$ Classcraft).

O excerto [1] deixa evidente a importância que Patrick dá à prática de leitura, salientando sua preferência e valoração à leitura de fanfictions. É comum, não apenas no contexto de realização deste estudo, a queixa de que os jovens, de diferentes posições socioeconômicas, não têm interesse nas práticas de leitura mais tradicionais, concebidas aqui como a leitura e a escrita do texto narrativo impresso, geralmente sugeridos pela escola.

Nosso objetivo, neste momento, não é o de levantar reflexões acerca do que caracteriza um leitor ou de problemáticas relacionadas à leitura no Brasil, embora acreditemos que sejam temáticas de grande relevância. Nosso intuito, a partir da fala de Patrick, é lançar um olhar acerca das motivações que impulsionam esses sujeitos a, durante suas horas de lazer, destinar tempo à leitura, à escrita ou à publicação de textos ficcionais em meio eletrônico, já que as práticas de leitura e escrita geralmente não são concebidas como atrativas para muitos jovens.

Há de se contestar o fato de que, por vezes, os jovens que iniciam seu percurso pelo universo fanfictional podem passar a ter uma intensidade maior de leitura desse gênero em comparação à leitura de outras obras literárias, impressas ou digitais e legitimadas socialmente. Essa problematização, ainda, pode caminhar na direção de que, por não se tratar de um gênero legitimado e pela forma como é produzido e disponibilizado, os conteúdos abordados em uma fanfiction não passam pela supervisão de uma comissão editorial, mas apenas pelo fandom, que não necessariamente irá atuar na qualificação do conteúdo desse texto. Apesar deste livre acesso dos jovens a esses conteúdos, em alguns casos impróprios, isso não implica dizer que esses conteúdos de livre acesso na internet sejam uma característica

10. Apesar de optarmos por utilizar o termofanfiction, para nos referir ao gênero em questão, mantivemos as características originais da fala e da escrita dos sujeitos, que optam por utilizar o termo fanfic.

11. O formato de escrita utilizado pelos estudantes na plataforma Classcraft foi mantido do decorrer deste artigo. 
apenas das fanfictions. Pelo contrário, são problemáticas que emergem por meio de diversas mídias desde a disseminação da internet.

Corroboramos a visão de Vargas (2015), ao inferir que, talvez, a afinidade pelas fanfictions seja inerente à oportunidade de esses jovens interagirem com textos de seu interesse por conta de, em sua grande maioria, estarem relacionados a momentos de entretenimento desses sujeitos. $\mathrm{O}$ grande apreço dedicado a narrativas fanficcionais veiculadas em diferentes plataformas que perpassam a vida e, portanto, o imaginário de um jovem, leva-o a se constituir um fã desse gênero. Nesse sentido a escola pode valorizar o apreço desses jovens por um gênero que tem contribuído na constituição deles como leitores e escritores e, a partir disso, inseri-los em práticas de letramentos com outros gêneros que fazem parte do escopo escolar.

Nessa perspectiva, a disseminação da internet tem aberto precedentes para certa segregação de grupos sociais permitindo que eles interajam apenas com conteúdos de seu interesse. Apesar de, em [1], Patrick inferir que "não acha legal" passar tempo nas redes sociais, este posicionamento pode ser um reflexo das vozes sociais (BAKHTIN, 2011) com as quais o sujeito interage diariamente. Os dados que emergem neste estudo indicam que o apreço que adolescentes possuem por redes sociais, que possibilitaram a interação entre pessoas que, geralmente, possuem a mesma faixa etária, os mesmos gostos, as mesmas práticas, influenciam diretamente nas práticas de letramentos escolares desses sujeitos, posicionando-se ora como insider ora como outsider (GEE, 2001). Isso não significa dizer que esses sujeitos não interagem a partir das demais práticas de letramentos em que são inseridos no contexto escolar. Porém, consideramos que a interação desses estudantes com práticas de leitura e de escrita por meio de eventos de letramentos com os quais possuem afinidade resultará em uma aprendizagem mais significativa.

As fanfictions, que nascem de uma atividade extraescolar com a especificidade de serem completamente voluntárias, são, muitas vezes, desconhecidas das comunidades escolar e familiar, mas altamente atrativas para quem com elas se envolve, conforme evidenciado nos excertos a seguir:

[2] Então, as fanfic sempre foram a minha paixão pq eu descobri elas [...] eu comecei a ler elas primeiramente fazem uns 3 anos, pq nesses 3 anos primeiro eu comecei com os imagines ${ }^{12}$ que são histórias bem menores do que as fanfic e depois eu descobri as fanfics [...] Eu descobri as fanfic por causa que, pq eu sou e sempre fui apaixonada pela banda one direction (Patrick, (lasscraft).

12. Imagines são histórias criadas com o intuito de interagir com o leitor, levando-o a se imaginar vivendo situações com o personagem em questão. Por isso, geralmente o protagonista é referida como $\mathrm{S} / \mathrm{N}$ ou $\mathrm{Y} / \mathrm{N}$, que seria "Seu Nome" ou "Your Name". 
[3] Então, eu comecei a ler Fanfic, foi tipo, já faz 5 anos na verdade, mais ou menos, não sei certinho, mas enfim, sempre que eu via um filme assim, uma série, eu ficava imaginando, tipo, esse universo alternativo que poderia ter dentro disso. [...] Eu leio num site que se chama spirit fanfics e histórias. Eu gosto porque a pessoa pode se identificar com alguma, pq tem de tudo né, fanfic sobre livro, séries, filmes, até sobre celebridade, sobre o presidente, enfim, alienígena, sobre o que tu quiser. (Bailey, Classcraft).

[4] [...] eu procurei e vi que tinha o Wattpad $^{13}$, que era esse app que tem milhões, meu, tem milhares, milhares, milhares de fanfics assim ó, eu sempre procurei da banda One Direction, mas de uns tempos pra cá eu comecei a ver da banda Five Seconds of Summer, que também me apaixonei, e aí nesse wattpad tem de vários artistas, tanto de séries, músicos, pessoas da televisão, é excelente. (Fable, Classcraft).

Inicialmente, os excertos [2], [3] e [4] refletem uma mudança nas práticas fora das instituições escolares, relacionadas à leitura e à escrita para o meio eletrônico, o que aponta para: a) a inserção desses sujeitos em práticas de letramentos com $\mathrm{TD}_{\text {; }}$ e b) para questionamentos acerca do tempo que esses sujeitos destinam às práticas de letramentos com TD envolvendo as fanfictions. Essas mudanças podem inferir a necessidade de transformações dentro do contexto escolar. A pesquisa desenvolvida por Barboza (2016) explica que embora práticas de letramentos envolvendo leitura e escrita com uso de TD sejam consideradas cansativas por gerações anteriores, autores e leitores de fanfictions parecem ter o hábito de passar uma média de 15 horas diárias navegando na internet, concentrados na busca e na leitura de histórias que têm relação com uma obra original pela qual todos os que participam de determinadas comunidades possuem apreço. As fanfictions produzidas por esses jovens autores e disponibilizadas na internet não estão publicadas em websites de cunho educacional, como os mantidos pelas escolas, que estão repletos de trabalhos elaborados para o cumprimento de requisitos em diferentes disciplinas. Essas obras, de caráter ficcional, são resultado de horas de trabalho e de dedicação espontâneos dos autores e são publicadas em websites construídos e gerenciados por outros internautas, também autores.

De acordo com estudiosos dos letramentos (GEE, 2000; 2001; STREET; LEA; LILLIS, 2015), a prática de leitura representa um percurso de construção de sentidos que se desenvolve à medida que o leitor busca no seu conhecimento de mundo os elementos que vai combinar, confrontar, interagir com os extraídos do texto lido. Os excertos [2], [3] e [4] deixam evidente o fato de que letramentos

13. O Wattpad é uma plataforma digital gratuita onde você pode ler histórias de escritores iniciantes e também publicar seus próprios textos. 
não ocorrem apenas na esfera escolar, mas nos muitos contextos de vivência desses sujeitos, e implicam sua inserção em atividades que exigem o uso da linguagem e do pensamento, "para fazer sentido de uma variedade de situações do dia a dia que se apresentam como oportunidades de aprendizagem" (VARGAS, 2015, p. 89).

Ainda, esses excertos apontam para a vivência dos sujeitos em torno de práticas de letramentos, que envolvem o universo das fanfictions, a partir de atividades que desenvolvem, como acompanhar uma banda com a qual têm afinidade, assistir a um filme etc. Essas atividades impulsionaram a inserção deles em práticas de letramentos, que permitiram a eles conhecer novos gêneros, como os imagines, e novas ferramentas, como o aplicativo Wattpad ou o site Spirit Fanfics. Para Vargas (2015), esses conhecimentos não se limitam à palavra escrita, pois, ainda, conferem aos sujeitos envolvidos nessas práticas a sensação de domínio da situação, decorrente do uso de suas habilidades linguísticas para o acesso a esses textos, como, por exemplo o uso de aplicativos para a leitura ou os usos da linguagem relacionada ao universo das fanfictions.

É a partir da familiarização com as fanfictions que surge, dos próprios sujeitos, a proposta de escrita de um texto do gênero, a partir da possibilidade de entrelaçamento com suas experiências de leitura anteriores. A proposta foi concebida por nós como uma possibilidade de inseri-los em práticas de letramentos que pudessem ser significativas, conforme apontam os excertos:

[5] tipo, tivemos que escrever tudo em inglês, claro né, mas não foi difícil, pq como a gente já tava familiarizado com a estrutura e com os temas e enfim, foi muito tranquilo, pelo menos pra mim foi bem tranquila assim [...] (Bailey, Classcraft).

[6] a gente usou gírias também, a gente usou coisas da atualidade tipo, que não é o que vai tá no livro tipo, o livro não vai mostrar gírias em inglês ou algumas expressões (Leviathan, grupo focal).

No excerto [5] o sujeito evidencia sua familiarização com fanfictions e com as temáticas referentes a esse gênero, porém, essa familiarização se deve a uma interação realizada apenas por meio das práticas de leitura em contexto não escolar, visto que nenhum dos sujeitos havia escrito uma dessas histórias. Ainda em relação à estrutura da fanfiction, Vargas (2015) destaca que esta forma narrativa se desenvolveu por meio de processos de interação social, à medida que os fandoms acrescentavam elementos sempre novos às fanfictions, geralmente relacionados ao mundo do entretenimento, para torná-las ainda mais significativas aos novos contextos de narração. Um exemplo de elementos atuais, que os fandoms acrescentaram às fanfictions, foram as 
histórias criadas a partir de polêmicas em torno das eleições americanas, em 2016, quando eleito o atual presidente dos Estados Unidos, Donald Trump e divulgadas em websites como o Spirit Fanfics.

Os estudos de Barboza (2016) apontam para a fanfiction como um gênero pouco explorado, sendo suas regularidades geralmente definidas pelos próprios fandoms. Com base nas buscas realizadas para este artigo, pode-se inferir que a fanfiction produzida pelos sujeitos (ANEXO A) se caracteriza como uma Ficlet, por conta de sua extensão, conforme abordado na Figura 1. A produção possui características do gênero, em sua composição como, a descrição inicial das personagens que compõem o texto, a faixa etária à qual a fanfiction se destina e o uso de personagens famosos do cotidiano desses sujeitos.

Em [6], ao inferir o "uso de gírias e coisas da atualidade" na fanfiction (ANEXO A) produzida, consideramos que os sujeitos se referem ao uso de uma linguagem informal, podendo, inclusive, ser identificado o uso proposital de expressões em língua portuguesa como "Kirido" e "recalcada", além de expressões em língua inglesa incluindo linguagem formal e informal como, "who are you?", usada no sentido de desprezo ao invés de seu uso regular "quem é você?". Ademais, algumas correções no texto foram solicitadas aos sujeitos, por meio da ferramenta de feedback da plataforma Classcraft, por serem observadas algumas questões gramaticais incoerentes, especialmente nos trechos em que o personagem Louro se manifesta, por exemplo: "Taylor, what bappen??". Entretanto, os sujeitos se posicionaram afirmando que optaram pelo uso de algumas expressões errôneas para representar a fala de personagens não nativos do idioma, indicando que, mesmo a partir desses erros, a mensagem em inglês foi transmitida.

A interpretação que tecemos a partir da indicação de uso de temas da atualidade, no excerto [6] foi referente aos usos de personagens famosos atualmente e de situações corriqueiras nas quais esses famosos se envolvem fora do contexto da fanfiction, como discussões, por exemplo. A afirmação se confronta com a ideia, também no excerto [6], de que a apostila, utilizada anteriormente nas aulas do Clube de Inglês, não apresenta determinadas gírias e expressões, o que nos orienta à ideia de que, para esses sujeitos, o uso da apostila representa uma prática um tanto quanto arcaica, por não fazer uso da linguagem informal, a partir da qual os adolescentes geralmente interagem.

As interpretações feitas a partir dos excertos anteriores não invalidam a prática de escrita da fanfiction, pois, conforme já mencionado, o relevante nos estudos de um gênero não é somente a aprendizagem de sua estrutura, mas, também, os conhecimentos que irão emergir a partir dos estudos desse gênero, sejam eles 
acerca da leitura e da escrita, ou de interações decorrentes dele, em que esses estudantes aprendem a se inserir. Esses conhecimentos são dependentes de práticas de letramentos em que esses estudantes serão envolvidos durante esse percurso.

Os dados abordados até o momento levantam discussões acerca de como poderiam ser mediadas interações na esfera escolar, na perspectiva desses estudantes, com base nos enunciados que emergem a partir da escrita da fanfiction:

[7] É que tipo, o livro é só o livro, tipo assim, tu vais fazer aquela atividade e pronto, vai ser tipo daquele jeito e pronto. E lá no clube, com o classcraft a gente podia fazer as coisas de diferentes maneiras e era muito mais light. Meu Deus, assim, no livro, eu não posso botar um meme ali no meio, eu não vou ter aquele tempo pra pesquisar, [...] e uma coisa que eu percebi, que é um exemplo que substitui muito o método tradicional ali, que deu pra render muito mais foi a fanfic por exemplo, porque a fanfic é um texto, é uma história praticamente né, só que cara, rendeu muito mais fazer lá [...] (Bailey, grupo focal).

O excerto [7] dá pistas acerca dos desafios que o professor encontra ao estar entre jovens cercados pelas informações, mas com dificuldade de controlar as emoções e incertezas sobre o que esse processo demanda. Esse desafio se amplia frente à realidade dos adolescentes de hoje, uma vez que eles fazem parte de uma geração com profundas conexões com as TD. Contudo, ressaltamos que não existem metodologias de aprendizagem perfeitas, pois os processos de ensinar e aprender possuem grande complexidade e envolvem diferentes fatores (IMHOFF; GRIMES; SCHROEDER, 2013) relacionados, principalmente, às experiências prévias desses sujeitos, às mediações desenvolvidas pelo docente e ao processo de internalização do conhecimento a partir de seus usos em diferentes contextos.

Segundo Vygotsky (1896-1934a, p. 115), "[...] o aprendizado humano pressupõe uma natureza social específica e um processo através do qual as crianças penetram na vida intelectual daquelas que as cercam". Nas práticas de letramento escolar, a mediação ou negociação do professor e as relações sociais de produção do conhecimento são fundamentais para o desenvolvimento dos estudantes. $\mathrm{Na}$ aprendizagem colaborativa, acontecem os processos contínuos de letramento, conceituado por Vygotsky (1896-1934a, p. 112), como a Zona de Desenvolvimento Próximo ou Proximal (ZDP):

A zona de desenvolvimento proximal é a distância entre o nível de desenvolvimento real, que se costuma determinar através da solução independente de problemas, e o nível de desenvolvimento potencial, determinado através da solução de problemas sob a orientação de um adulto ou em colaboração com companheiros mais capazes. 
A ZDP possibilita o acompanhamento, por parte do professor, dos ciclos completados e os ciclos que ainda se encontram em desenvolvimento, os ciclos contínuos de aprendizagem, permitindo, assim, a caracterização das competências dos estudantes e suas conquistas, bem como, a elaboração de orientações pedagógicas que ajudam nesse processo de colaboração com o outro (REGO, 2000).

Complementando os enfoques anteriores, as relações sociais, no contexto educativo, possibilitam as trocas de conhecimentos vivenciados pelos estudantes com os conhecimentos aprendidos no ambiente escolar, resultando, assim, no desenvolvimento cognitivo dos adolescentes. Deste modo, os processos contínuos de letramento escolar permitem a negociação entre o professor e os estudantes, em que o professor introduz os estudantes no universo conceitual, por meio de suas vivências. As relações sociais, em sala de aula, permitem ao professor realizar uma aproximação entre os conhecimentos espontâneos experienciados pelos estudantes e os conhecimentos científicos ensinados no ambiente escolar.

Levando em conta as considerações feitas pelo sujeito no excerto [7], as TD assumem importante papel dentro das práticas de letramentos deste estudante. Nesse sentido, há de se considerar, com base em [7], menções a uma dicotomia entre a ideia de uso da apostila relacionado à escola, como espaço tradicional de ensino, e o uso das TD ligado à escola como um ambiente de aprendizagem que considere as trajetórias de aprendizagem desses sujeitos.

Porém, deve-se considerar, retomando a fala de Vygotsky (1998), que o professor é uma peça importante para a mediação das práticas com essas TD, pois para que essas tecnologias possam de fato promover interação dos estudantes em práticas de letramentos, de modo mais democrático, é necessário que sejam, além de somente equipados com TD, incluídos digitalmente (BUZATO, 2009). A defesa deste autor é pela inserção em práticas que problematizem os usos dessas TD. No caso do âmbito escolar, o professor pode ser a pessoa responsável ou encaminhar essa problematização, a fim de que as TD não sejam relacionadas apenas com usos para o lazer desses sujeitos. Caso contrário, os trabalhos em torno da TD podem contribuir para uma maior deslegitimação do ambiente escolar, por estarem diretamente relacionadas à ideia de usos para lazer desses sujeitos. Buzato (2009) afirma que, para que essa inclusão ocorra, inicialmente, são necessárias duas condições: o acesso à infraestrutura técnica mínima e um grau mínimo de capacitação da população para o uso das TD (BUZATO, 2009, p. 2). Sendo a escola um dos principais meios de acesso dos estudantes às TD, logo, é pertinente que também forme cidadãos para interagir numa sociedade de convergência de mídias (BUZATO, 2009; ROJO, 2012). Em relação aos excertos [8], [9] e [10], que seguem, manifesta-se a satisfação 
dos sujeitos em atividades de cunho colaborativo durante a inserção nas práticas de letramentos de escrita da fanfiction.

[8] eu aprendi tipo além do inglês, mais sobre a fanfic, o que é, eu que não sou desse meio eu aprendi, eu pude aprender com meus amigos [...] então, ficou um trabalho que a gente fez, que a gente gostou e não um trabalho que a gente fez pra agradar e pra alcançar nota sabe, sabe, foi uma coisa muito mais pra gente do que pra alcançar nota (Rogue, grupo focal).

[9] todos que leem sempre vão ter ideias e coisas pra escrever, e conforme a gente foi escrevendo, fomos fazendo juntos, trocando as ideias, a, vamos colocar isso, vamos colocar que isso acontece, ai agora coloca fulano no meio dessa história, o que é bem legal e é bem descontraído, porque, tipo, tivemos que escrever tudo em inglês (Fable, grupo focal)

[10] A gente utilizou no classcraft, na aula de inglês, com o drive, que a gente podia compartilhar, ou seja, era um grupo, e a gente criava histórias juntos (Bailey, grupo focal).

Os enunciados deixam pistas da inserção dos sujeitos em diferentes práticas de letramentos a partir da escrita da fanfiction, seja por meio da troca de conhecimentos entre estudantes que possuíam contato com o gênero e estudantes que não possuíam e puderam inserir-se em uma prática colaborativa de escrita, seja pelo uso de diferentes tipos de TD, como o Classcraft e o google docs, que indicam e permitem novas formas de inserção em práticas de letramentos, dentro e fora da escola.

Nessa perspectiva, Vygotsky (1896-1934b) ressalta que o afeto influencia diretamente no desenvolvimento do cognitivo dos indivíduos, no ato de pensar, a motivação, a necessidade, os interesses, dentre outros sentimentos que movimentam e direcionam o pensamento. Do mesmo modo, o pensamento influencia também na parte afetiva e volitiva do ser humano, isto é, no seu comportamento. O excerto [11] ainda traz apontamentos relevantes acerca da aprendizagem ligada à afetividade:

[11] A aula do clube, o classcraft ele ajuda porque a gente não, não é que o livro não ensina, é que aí a gente aprende mais a parte técnica do inglês, a, onde que vai o verbo, mas tu vai chegar lá com um gringo tu não vai ficar pensando "hum... aonde é que eu boto essa palavra? Como é que eu falo agora?" E aí no classcraft a gente meio que já pratica isso escrevendo na fanfic (Leviathan, grupo focal).

O excerto [11] indica, na concepção do estudante, que a abordagem utilizada para o ensino da língua inglesa no Clube, antes dos trabalhos com as fanfictions, não se relacionava com os usos do inglês em um contexto real de interação, por estarem ligados, basicamente, a classificações metalinguísticas. De acordo com Street, 
Lea e Lillis (2015), é falha a ideia de que se pode adotar uma visão padronizada e restrita do inglês, transformando-o no padrão para pessoas que estão migrando para o sistema, pois isso não funciona na prática comunicativa real. Para o autor, considerando o ensino de língua inglesa, deve-se considerar que os sujeitos estão "vindo de uma experiência tão mista da vida cotidiana que esse modelo dominante padronizado [...] não tem muita relação com o mundo em que elas estão realmente vivendo" (STREET; LEA; LILLIS, 2015, p. 388, tradução nossa), especialmente em se tratando de falantes não nativos do idioma. Um ensino baseado na concepção normativa de língua pode ser usado por um tempo para definir supostas regras, assinalar algum tipo de sotaque e essa gramática, mas uma vez que esses sujeitos são inseridos em situações que exigem o uso da segunda língua, uma abordagem padrão parece bastante singular e irrelevante.

Em uma perspectiva dos estudos dos letramentos, a prática de escrita da fanfiction envolveu um olhar de perspectiva etnográfica (LILLIS, 2008) permitindo acompanharmos mais de perto o que os estudantes trazem ao Clube de Inglês e, a partir disso, houve as negociações entre professores e estudantes no que concerne ao que envolveria essa atividade. Cabe destacar, no excerto [11], o reconhecimento do sujeito perante a aprendizagem normativa do idioma advinda a partir da apostila, o que não representa um desmerecimento a esse tipo de abordagem para o ensino do idioma, que pode ser utilizado em diferentes práticas de letramentos em diferentes esferas e situações. No contexto atual de vivência desses estudantes, porém, suas necessidades em relação aos usos da língua são outras, que não as representadas no livro didático e, por isso, demonstram afinidade tanto com a aprendizagem do idioma com base em gamificação, quanto aos recursos utilizados nesse percurso, como as TD e o gênero fanfiction.

O enunciado de Leviathan, em [11], se relaciona com os resultados de uma pesquisa desenvolvida por Fischer e Komesu (2018) sobre letramentos acadêmicos, TD e gamificação. As autoras afirmam que estudantes de Ensino Médio destacam alguns aspectos sobre o ensino da língua inglesa dentro do ambiente escolar, muitas vezes caracterizando esse aprendizado como desvinculado das práticas sociais do sujeito, indicando que fora do ambiente formal, muitas vezes as normas cultas abordadas na escola não serão necessárias, assim como Leviathan menciona o uso da apostila como ferramenta de ensino normativo. Para Leviathan, e conforme os resultados de Fischer e Komesu (2018), o aprendizado escolar do idioma é associado a uma identidade legislativa da escola. Para os estudantes, esse tipo de aprendizagem se torna mecânica e sem sentido, uma vez que necessitam utilizar de procedimentos padrões predefinidos que não lhes são exigidos fora do contexto escolar. 
No excerto [12] há marcas da valoração ao modo adotado para a inserção dos sujeitos na prática de escrita da fanfiction:

[12] eu não precisei de uma aula sobre como é uma fanfic é, tipo, alguém me mostrando a estrutura de uma fanfic, não, é eu acho que é assim que tem que ser o ensinamento do inglês, ou o aprendizado do futuro sabe, tem coisas que não precisa mais ensinar, por exemplo, quando tu vai jogar um jogo quem é que lê o tutorial do jogo? (Patrick, grupo focal).

A fala no excerto [12] remete a uma metodologia de ensino a partir da Sala de Aula Invertida - SAI (LEFFA; DUARTE; ALDA, 2016), em que a aprendizagem pode ocorrer tanto dentro quanto fora da sala de aula. Para esses autores, a escola e o contexto em torno dela não representam espaços isolados. Pelo contrário, há uma reciprocidade entre os dois, direcionando a aprendizagem ora para um lado, ora para outro. Ao considerar a aprendizagem pelo sistema de SAI, o estudante inicia a aprendizagem fora do ambiente escolar e termina na sala de aula, onde, trabalhando em grupo, elabora uma determinada tarefa e apresenta os resultados ao grande grupo.

Para refletir sobre o papel da SAI nos processos de ensino e de aprendizagem nos contextos escolares, pode-se discutir sobre o processo de construção de conceitos proposto por Vygotsky e seus colaboradores. Nesse sentido, de acordo com Vygotsky (1896-1934c), no desenvolvimento da consciência é necessário que ocorram os processos de construção dos conceitos científicos na ZDP dos estudantes, e para atingir o pensamento conceitual, eles necessitam alcançar determinado nível de consciência para a internalização do conhecimento. Dessa forma, com a mediação docente e a colaboração dos colegas, os sujeitos do Clube têm a oportunidade se desenvolver usos de conhecimentos e ampliar suas ideias, num processo cíclico e dinâmico.

Nesse sentido, segundo Vygotsky (1896-1934c), o conhecimento do contexto social e cultural dos estudantes pelo docente é fundamental para a aprendizagem dos indivíduos, que tem início muito antes de sua entrada na escola. Além disso, a aprendizagem escolar se baseia (ou deveria basear-se), também, no estágio de desenvolvimento já percorrido pelos estudantes.

No excerto [12] há indícios de uma menção valorativa, por Patrick, ao uso do método de SAI que vai em direção oposta às metodologias de ensino de cunho transmissivo com as quais os estudantes estavam habituados no Clube, ao afirmar "eu não precisei de uma aula sobre como é uma fanfic é, tipo, alguém me mostrando a estrutura de uma fanfic" e "têm coisas que não precisa mais ensinar". O enunciado de Patrick dá indícios do método SAI, pois refere-se ao fato de que o impulso para 
a aprendizagem com fanfictions não partiu de uma abordagem de ensino estrutural do gênero, como suas partes composicionais. A proposta de trabalho com fanfictions, já descrita na seção 3, vislumbrou sujeitos ativos no percurso de aprendizagem do gênero, a partir da inferência de Leffa et al. (2017) quando afirmam que há várias maneiras de iniciar a aprendizagem de um determinado conteúdo, como pesquisando ou lendo. O desafio para o professor, portanto, é propor uma atividade que deixe o estudante interessado e com desejo de aprender mais, para isso, relacionando o conteúdo a ser aprendido com a experiência de vida, interesses e necessidades que o estudante traz para a escola.

Apesar das valorações feitas pelo sujeito, em [12], à abordagem de ensino, consideramos relevante problematizar o fato de que, por conta de fatores como a necessidade do cumprimento de um cronograma pela docente, não houve na prática de ensino a sistematização sobre a organização estrutural da fanfiction durante as aulas do Clube de Inglês. Os conhecimentos utilizados pelos alunos na escrita da fanfiction foram aqueles advindos de suas trajetórias com o gênero, pesquisas acerca desses textos no período extraclasse para posterior diálogo em sala de aula acerca do gênero na relação com as mediações desenvolvidas pela professora. Nosso objetivo não é o de inferir que a SAI se sobrepõe aos demais métodos que podem ser utilizados em contextos de aprendizagem. Há de se considerar, ainda, que os usos de diferentes metodologias não são sinônimo de mera transposição didática e que vários fatores influenciam na reelaboração dessas abordagens em sala de aula. No caso da SAI, entretanto, seu uso pode resultar na falsa impressão de que essa abordagem não pode contar com mediações de um professor para ser legitimada. Entretanto, conforme discute Leffa et al. (2017) e como ocorrido no trabalho com as fanfictions, a ideia do método SAI foi o de impulsionar as atividades iniciais com o gênero, por meio das buscas e da roda de conversa com os alunos. As posteriores mediações feitas pela professora durante as aulas do Clube foram necessárias para que os conhecimentos desses sujeitos em torno do gênero pudessem ser aprimorados.

Nesse sentido, a reflexão que tecemos é a de que o trabalho com a fanfiction, a partir do método de SAI, pode ser utilizado para obter uma reação resposta dos sujeitos à introdução a outras obras literárias valorizadas no escopo de interesse do ano letivo, podendo resultar em um hibridismo entre práticas no contexto escolar e fora dele. Para que a proposta de estudos a partir da metodologia de SAI ocorra, conforme Leffa, Duarte e Alda (2016), é relevante que o estudante consiga relacionar a proposta apresentada pelo professor com sua experiência prévia de mundo para fazer a conexão entre o que precisa aprender e o que já sabe, de modo que o conteúdo faça sentido para ele. Quanto mais conexões conseguir estabelecer, 
maior será o engajamento e, consequentemente, mais relevante a aprendizagem. Por outro lado, quanto menor a contribuição do conhecimento já adquirido pelo estudante, menor será o número de conexões, resultando em uma aprendizagem também menor.

[13] de novo é o exemplo da fanfic, que é uma coisa que a gente gosta e a teacher trouxe pro Clube de Inglês e do clube a gente levou pra fora. A gente pôde ler alguma (fanfic) em inglês, então o inglês passou a fazer parte do nosso processo. Porque a fanfic, quando a gente tava no processo de criar ela, podemos ter pensado um pouco em português, mas o clube fez o processo de transformar em inglês. Quando transformou em inglês teve o aprendizado, teve o aprendizado das gírias, sobre como é o texto fanfic e quando voltou de volta pra nossa vida, ele voltou tanto sendo história em português que a gente teve uma ideias e também como foi a história em inglês que a gente criou no clube, [...] então o clube fez parte desse processo da nossa vida. Por que não pode ser sempre dessa forma aliada da gente, sem pressão, o processo ocorreu naturalmente e demonstrou um processo muito maior ainda do que seria se a aula fosse de outro jeito, como com o livro na sala de aula, ou fazendo prova, fazendo isso, fazendo aquilo, eu acho que sim que o rendimento foi muito maior e foi muito melhor (Rogue, grupo focal).

A partir do depoimento [13], refletimos que: a) é evidente a preferência do sujeito por uma aprendizagem ativa, não apenas lendo, ouvindo ou assistindo passivamente, mas interagindo e construindo novos sentidos a partir de conhecimentos prévios; b) a ampliação do espaço de aprendizagem, que pode ocorrer em qualquer lugar e hora e não, necessariamente, entre as paredes da sala de aula ou em um horário fixo; c) a necessidade de o sujeito ser ativo no percurso de aprendizagem, principalmente por meio da inserção deles em práticas de letramentos que lhes possibilitem vivenciar ou mostrar seus conhecimentos; e d) o fato de não haver julgamentos negativos constantes, por parte do professor e dos colegas de equipe, neste caso em análise, viabilizou a valoração à prática gamificada também em âmbito escolar.

No que se refere a preferências, especialmente àquelas relacionadas ao ensino de línguas, os estudos de Leffa et al. (2017) indicam que, na percepção dos estudantes, um bom professor de línguas estrangeiras é aquele que inspira os estudantes, assume a autoridade quando necessário e gosta de ensinar. As caracterizações mencionadas por Leffa reforçam que não basta enaltecer a presença defanfictions, ou outros gêneros circulantes em meios digitais, unicamente; o professor também é protagonista neste cenário de produção. Os estudantes esperam que o professor tenha senso de humor, autodisciplina, calor humano, entusiasmo e mente aberta, segundo os autores citados. Finalmente, desejam que ele seja competente, 
criativo, eficiente, flexível, honesto, humilde, organizado, paciente, prestimoso, sensível e tolerante. No geral, são expectativas de estudantes, o que não representa que sejam imposições ao perfil do professor. Permanece, e muito, um senso comum relativo a um perfil pedagogicamente correto. Por outro lado, como Leffa (2008) já indicava na primeira década dos anos 2000, o que se deseja - tanto por parte da academia e dos ambientes formais de ensino - é que o professor de línguas seja reflexivo, crítico e comprometido com a educação, o que lhe abre possibilidades de escolhas e práticas situadas de ensino e aprendizagem.

\section{CONSIDERAÇÕES FINAIS}

Por meio do percurso de pesquisa que se estende desde o primeiro contato com os sujeitos até às análises dos dados para este estudo, pode-se inferir que as práticas ocorridas em torno das fanfictions, a partir do Clube de Inglês, inserem-se em um modelo dialógico de letramentos (FISCHER, 2007). Inspirado no modelo dos letramentos acadêmicos (LEA; STREET, 2007), engloba questões como a construção de sentidos, as identidades socialmente situadas, as relações de poder e de autoridade intrínsecas às práticas de letramentos de sujeitos, neste caso, no contexto escolar.

As questões mencionadas como integrantes do modelo dialógico dos letramentos ficam evidentes no trabalho com o gênero fanfiction, que permitiu aos estudantes evidenciarem particularidades relacionadas a diferentes práticas de letramentos que emergem a partir da fanfiction. Um exemplo que comprova o dizer anterior são suas preferências quanto ao uso das TD nas práticas de letramentos que resultaram dos trabalhos com o gênero, as quais indicaram diferentes usos que esses sujeitos fazem da leitura e da escrita, seja pelas formas de pesquisar, de se inserirem em práticas de leitura e escrita, como aquelas feitas por meio de aplicativos, seja pelo uso de memes ou de gírias. Acreditamos que o trabalho com as fanfictions conferiu aos sujeitos a sensação de controle quando inseridos em um contexto de aprendizagem, decorrente do uso de seus conhecimentos prévios sobre o gênero e sobre o universo que o permeia.

A partir da escrita gamificada, os sujeitos deixaram evidentes diferentes formas de agir e de construir conhecimento como, por exemplo, por meio da troca de informações entre os integrantes do grupo e por meio de buscas realizadas na internet. Como pesquisadoras, compreendemos que o trabalho gamificado com a fanfiction deu aos estudantes autonomia e confiança para traçarem seu próprio percurso de aprendizagem, não sendo necessário o constante uso de instruções por 
parte das docentes. Destaca-se, ainda, que a tentativa de uso de uma abordagem no modelo de Sala de Aula Invertida quebrou a verticalização presente em tantos contextos de ensino em nosso país, possibilitando que os estudantes fossem construtores do próprio conhecimento a partir de suas vivências e o professor atuando como um mediador das práticas e não como um regulador.

Os resultados deste estudo reforçam a possibilidade de a escola levar em conta os diferentes letramentos que constituem trajetórias de estudantes com identidades tão distintas. É a partir dessa multiplicidade de letramentos que a escola pode inserir seus estudantes em práticas que realmente possibilitem a construção de sentidos e sejam significativas tanto a professores quanto a esses estudantes. $\mathrm{O}$ professor também necessita se sentir em constante interação com outros modos de produção de propostas metodológicas e não apenas reproduzir o discurso do déficit de que estudantes são mais competentes em fazer uso de recursos digitais. Negociação e interação indicaram, neste estudo, que são caminhos para construções mais colaborativas e oportunizam o ensino e a aprendizagem da escrita em uma perspectiva mais dialógica, partindo da perspectiva sociocultural dos letramentos.

A partir das considerações anteriores e em reação a muitos discursos que também visam deslegitimar o trabalho com gêneros, como as fanfictions, que circulam na internet, emergem questionamentos no presente estudo: a) por que a escola não pode ser o lugar em que se discutem temáticas transversais relacionadas às fanfictions? A exemplo pode-se citar questões voltadas às formas de censura dos textos com conteúdos considerados impróprios para menores de idade ou discussões em torno de fanfictions que tratam de temáticas relacionadas à problemáticas sociais e questões políticas; b) como a escola está dando atenção, não somente ao ensino, mas a elementos que compõem esse gênero? Por exemplo, sobre como ocorre a constituição colaborativa de autores na escrita das fanfictions ou colaborações entre os integrantes dos fandoms.

A experiência e os resultados advindos com o trabalho e análises das práticas de letramentos com as fanfictions indicam o quão produtivo é oportunizar que os alunos leiam e escrevam textos pertencentes a esse gênero, seja por caminhos que caracterizam a SAI ou outras metodologias, pois os insere em práticas de letramentos escolares significativas. Caso professores ou alunos não possuam experiências com gêneros desse tipo, em trajetórias anteriores, recomendamos o uso de abordagens que abarquem e contextualizem as trajetórias e conhecimentos prévios dos estudantes, como as utilizadas por nós neste estudo, com vistas à tentativa de promover maior motivação e engajamentos em práticas de letramentos. A produção escrita de gêneros já valorizados pela e na escola não são desvalorizados 
quando ocorre o trabalho com outros ainda não legitimados. Pelo contrário, esses gêneros, que não tão frequentemente são tratados na esfera escolar, mas que são de conhecimento dos estudantes, podem servir como motivação e influência para o relacionamento desses sujeitos com outros gêneros integrantes do escopo escolar.

Por fim, os dados apontam que, a partir do trabalho com as fanfictions, na relação com a gamificação e a abordagem de SAI, os sujeitos foram inseridos em práticas significativas de escrita em língua inglesa que não ocorriam, até então, no Clube de Inglês, por conta das abordagens de cunho normativo. Os dados indicam, ainda, que os movimentos desenvolvidos no Clube podem servir como uma motivação para a inserção desses sujeitos em práticas de escrita em demais disciplinas escolares, o que pode acarretar na fuga do discurso do déficit (GEE, 2001) em torno da produção escrita desses estudantes.

\section{$\overline{\text { REFERÊNCIAS }}$}

BARBOZA, C. M. M. M. (2016). Invadindo as masmorras - apropriações criativas, autoinserção (fan) ficcional e a emergência de uma intersubjetividade discursiva: uma etnografia do grupo snapetes à luz do pensamento bakbtiniano. 2016. Tese (Doutorado em Letras) - Programa de PósGraduação em Letras, Universidade Católica de Pelotas, Pelotas.

BAKHTIN, M. (1952-1953/1979). Os gêneros do discurso. In: BAKHTIN, M. Estética da criação verbal. 6. ed. Trad. Paulo Bezerra. 6. ed. São Paulo: Martins Fontes, 2011. pp. $261-270$.

BARTON, D; HAMILTON, M. (2000). Literacy practices. In: BARTON, D.; HAMILTON, M.; IVANIC, R. Situated literacies: reading and writing in context. London: Routledge, pp. 7-15.

BUZATO, M. EL K. (2009). Letramento e inclusão: do estado-nação à era das TIC. Delta, São Paulo, v. 25, n. 1, p. 1-38. Disponível em: http://www.scielo.br/scielo.

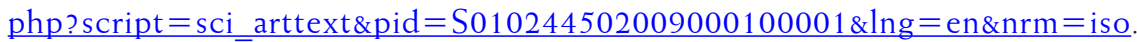
Acesso em: 10 abr. 2019.

DETERDING, C. S.; DIXON, D.; KHALED, R.; NACKE, L. (2011). From Game Design Elements to Gamefulness: Defining "Gamification". Proceedings of the 15th International Academic MindTrek Conference: Envisioning Future Media Environments, September 28-30, Tampere, Finland. Disponível em: http://www.rolandhubscher. org/courses/hf765/readings/Deterding_2011.pdf. Acesso em: 29 mai. 2019. 
FISCHER, A. (2007). A construção de letramentos na esfera acadêmica. 2007. Tese (Doutorado em Linguística) - Programa de Pós-Graduação em Linguística, Universidade Federal de Santa Catarina, Florianópolis.

FISCHER, A. (2011). Práticas de letramento acadêmico em um curso de Engenharia Têxtil: o caso dos relatórios e suas dimensões escondidas. Scripta, Belo Horizonte, v. 15, n. 28, p. $37-58,1^{\circ}$ sem. 2011.

FISCHER, A.; KOMESU, F. C. (2018) Letramentos acadêmicos e tecnologias digitais: visões do professor em serviço sobre gamificação na aprendizagem de língua estrangeira. In: Seminário Gel, 66., São José do Rio Preto. Simpósio de convidados. São José do Rio Preto: Unesp.

FRITZEN, M. P. (2012). O olhar da etnografia no fazer pesquisa qualitativa: algumas reflexões teórico-metodológicas. In: Fritzen, M. P.; Lucena, M. I. P. (orgs.), O olhar da etnografia em contextos educacionais: interpretando práticas de linguagem. Blumenau, SC: Edifurb, pp. 55-71.

GEE, J.P. (2005). GoodVideo Games and GoodLearning.PbiKappaPbiForum, v.35, n.2. Disponível em: http://www.jamespaulgee.com/sites/default/files/pub/GoodVideoGamesLearning. pdf. Acesso em: 19 jul. 2018.

GEE, J. P. (2001). Reading as situated language: a sociocognitive perspective. Journal of adolescent \& adult literacy, n. 44, v.8, pp. 714-725. Disponível em: http://jamespaulgee. com/pdfs/Reading\%20as\%20Situated\%20Language.pdf. Acesso em: 20 abr. 2019.

GEE, J. P. (2000). The new literacy studies: from socially situated to the work of the social. In: BARTON, D.; HAMILTON, M.; IVANIC, R. Situated Literacies: reading and writing in context. London: Routledge, pp. 180-196.

IMHOFF, A. M. V. G.; GRIMES, C.; SCHROEDER, E. (2013). Percepções de jovens aprendizes sobre os processos de ensinar e aprender. Linbas Críticas, Brasília, DF, v. 19, n. 38 , p. $169-186$, jan./abr.

KLEIMAN, A. B. (2010). Trajetórias de acesso ao mundo da escrita: relevância das práticas não escolares de letramento para o letramento escolar. In: Revista Perspectiva, Florianópolis, v. 28, n. 2, pp. 375-400.

LEA, M. R.; HAMILTON, M.; GOURLAY, L. (2014). Textual practices in the new media digital landscape: messing with digital literacies. Researcb in Learning Technology. 
vol. 21. Disponível em: https://journal.alt.ac.uk/index.php/rlt/article/view/1442/ pdf_1. Acesso em: 18 maio 2019.

LEA, M. R.; STREET, B. V. (2007). The "academic literacies" model: theory and applications. In: SIGET - SIMPÓSIO INTERNACIONAL DE ESTUDO DOS GÊNEROS TEXTUAIS, 4, Tubarão. Anais. Tubarão: Unisul, 2007. p.227-236.

LEFFA, V. J.; COSTA, A. R.; BEVILÁQUA, A. F.; FIALHO, V. R. (2017). Preferência dos estudantes na aprendizagem de línguas em três atividades do Moodle. Revista Brasileira de Linguística Aplicada, Belo Horizonte, v. 17, n.1, pp. 113-136.

LEFFA, V. J.; DUARTE, G. B.; ALDA, L. S. (2016). A sala de aula invertida: o que é e como se faz. In: JORDÃO, C. M. (org.), A linguística aplicada no Brasil: rumos e passagens. Campinas: Pontes. pp. 365-386.

LEFFA, V. J. (2008). Aspectos políticos da formação do professor de línguas estrangeiras. In: LEFFA, V. J. (org.), O professor de linguas estrangeiras: construindo a profissão. 2. ed. Pelotas: Educat, pp. 353-376.

LEFFA, V. J. (2007). Pra que estudar inglês, profe?: auto-exclusão em língua-estrangeira. Claritas, São Paulo, v. 13, n. 1, pp. 47-65.

LILLIS, T. M. (2008). Ethnography as Method, Methodology, and "Deep Theorizing": Closing the Gap Between Text and Context in Academic Writing Research. Written Communication, v. 25, pp. 353-388.

MARCUSCHI, L. A. (2008). Produção textual, análise de gêneros e compreensão. São Paulo: Parábola Editorial.

MCGONIGAL, J. (2011). Reality Is Broken: Why Games Make Us Better and How They Can Change the World. Nova York, Penguin Press, Ed. 1. Trad. Eduardo Rieche. BestSeller: Rio de Janeiro, 2011.

ROJO, R. (2012). Pedagogia dos multiletramentos: diversidade cultural e de linguagens na escola. In: ROJO, R.; MOURA, E. (org), Multiletramentos na escola. São Paulo: Parábola Editorial. pp. 11-32.

SCHMITZ, V. (2017). Um clube... na escola: identidade e interfaces com a educação (não formal) a partir de uma revisão sistemática. Dissertação (Programa de Pós Graduação em Educação). Universidade Regional de Blumenau. Blumenau. 
STREET, B.; LEA, M. R.; LILLIS, T. (2015). Revisiting the question of transformation in academic literacies: the ethnographic imperative. In: LILLIS, T.; HARRINGTON, K.; LEA, M. R.; MITCHELL, S. Working with academic literacies: case studies towards transformative practice. Anderson, South Carolina: Parlor Press; Fort Collins, Colorado: WAC Clearinghouse.

STREET, B. (2003). Abordagens Alternativas ao Letramento e Desenvolvimento. Apresentado durante a Teleconferência Unesco Brasil sobre 'Letramento e Diversidade’. Londres.

VARGAS, M. L. B. (2015). O fenômeno fanfiction: novas leituras e escrituras em meio eletrônico. Passo Fundo: Universidade de Passo Fundo. Disponível em: http://editora.upf.br/images/ ebook/o fenomeno fanfiction.pdf. Acesso em: 27 abr. 2019.

VIANNA, Y.; VIANNA, M.; MEDINA, B.; TANAKA, S. (2013). Gamification. In: Como reinventar empresas a partir de jogos. MJV Press: Rio de Janeiro.

VYGOTSKY, L. S. (1896-1934a). A formação social da mente: o desenvolvimento dos processos psicológicos superiores. Org. Michael Cole. Trad. José Cipolla Neto, Luís Silveira Menna Barreto, e Solange Castro Afeche. 6. ed. São Paulo: Martins Fontes, 1998.

VYGOTSKY, L. S. (1896-1934b). A construção do pensamento e da linguagem. Trad. Paulo Bezerra. São Paulo: Martins Fontes, 2001.

VYGOTSKY, L. S. (1896-1934c). Psicologia Pedagógica. Trad. Claudia Schilling. 2. Ed. São Paulo: Martins Fontes, 2004.

WENGER, E. (2004). Communities of practice: a brief introduction. Disponível em: < http://wengertrayner.com/introduction-to-communities-of-practice/>. Acesso em: 20 jan. 2019.

ZAVALA, V. (2010). Quem está dizendo isso?: letramento acadêmico, identidade e poder no ensino superior. In: VÓVIO, C.; SITO, L.; DE GRANDE, P. Letramentos: rupturas, deslocamentos e repercussões de pesquisas em linguística aplicada. Campinas, SP: Mercado de Letras. 


\section{ANEXO A - A FANFICTION PRODUZIDA PELOS SUJEITOS}

Characters:
Lorde
Fausto Silva
Harry Styles
Taylor Swift
Xuxa
Louro José
Anitta
Ana Maria Braga
Roberto Carlos
THIS IS THE FIRST PART OF A FANFICS
TRILOGY
ALLOWED TO ALL AGES - Published on
october 2018
"Nome dos autores retirados da produção por
questōes éticas
Title: A series of unfortunate events of pride
and prejudice

Fausto Silva: Good afternoon everyone, today in the "Domingão do Faustão", we'll meet 3 artist of the pop music AND, a former singer who paid me to sing in the program, with you, the queen of the "Baixinhos", XUXA MENEGHEWJJHDWDLNK.

Xuxa: Hellow, I like music, I love you, My name is Xuxa, Please Taylor Help me

\section{(Taylor Arrives)}

Taylor: $\mathrm{Hi}$, It is so nice being here.

Xuxa: Even more that your ex is here, when another song comes out (Fake laugh)

Taylor: Please, stop, I'm doing better that I ever was. (She goes out crying)

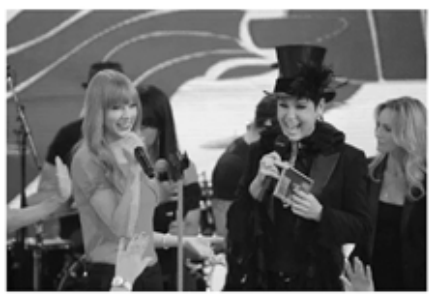

Fausto: Ok, so, now, come here to stop the fight, Harry Styles.

Harry Styles: Hey my loves, today I will talk about an event that occurred to me... Someone in this stage, made me fall in front of my fans, i cry a lot everyday, and I'll warn you, whoever did this will pay!

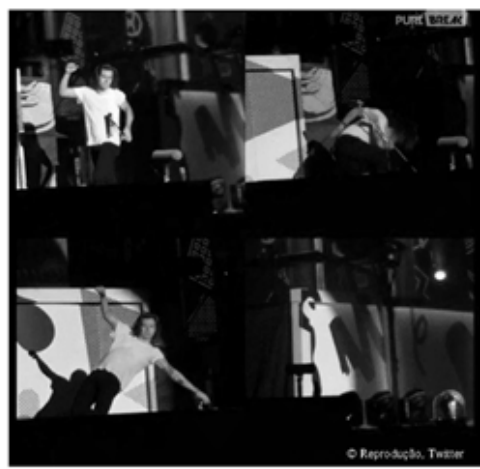

Fausto: $\mathrm{OHNO}$, who would sabotage our show?

Harry: I think that Lana Del Rey could have done this...

\section{(Lorde Arrives)}

Lorde: Shut Up, I'm not Lana Del Rey, please respect me!!!!!

(While they were arguing, Taylor, to distract the public, arrives singing IKYWT, but she fells in the stage)

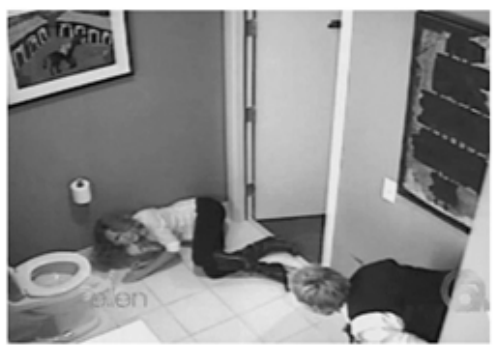



Louro: Taylor, what happen??
SOCORROOOOOOOO.

Fausto: Now, let's see a half-hour documentary about omega 3 .

\section{(CAM OFF)}

The artists gather in a room, to talk about what happened to the wonderful Harry, starting one "treta"...

Lorde: Hey 'KIRIDO" Do you think I should have lost my precious time with you?

Harry: Stop "recalcada", I know you're jealous of Taylor because of me.

Lorde: I know about what you did, and I wanna scream the true.

Taylor: I KNEW YOU WERE TROUBLE WHEN YOU WALKING.

Xuxa: How to be a singer who just made money with boys

Taylor: SORRY???? I'm one of the best singers of the world, who are you?

\section{Harry: STOP YOU TWO}

Fausto: YEAH, i'm trying to talk with Selena.

Louro: I think the fault is xuxa's, because she's the one who wasn't on stage

Xuxa: SORRY??? you were in the stage?

Taylor: Sorry??? you copied me?

Harry: I think that the fault is IORDE'S, BECAUSE SHE'S DOING BLACKMAIL WITH ME.

Lorde: It's not my fault if you do not assume your mistakes.

Louro: VERDADI, FRIENDS DO NOT LEAVE OTHERS UNDER ANY CIRCUMSTANCES

Fausto interrupts the conversation

Fausto: GUYSSSSSS, WE ARE LOSING THE AUDIENCE. Get back on the stage NOW..

Louro: Bye guys, my friend Ana is calling me
Harry: WHATTT? 2 seconds ago you were talking about friendship, and are you leaving already?

Louro: Shup Up "anta", KKKKKKKKKKK Just to remember, I hope your ass is broken

At this moment everyone in the room is surprised, and Loro José disappears quickly.

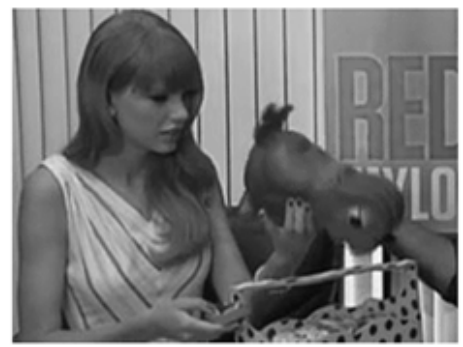

Louro went to the house of her BFF Ana Maria Braga, who was with to Anitta

Ana: So, and my plan to destroy the "Domingão do Faustão", worked?

Louro: In 3 days, I believe everyone will have a crisis that ended the show.

Anitta: NOOOOOOOOOOOOO, 3 DAYS, THAT NEEDS TO HAPPEN BEFORE, THE "MAIS VOCÊ" WILL NEVER DOMAIN THE TELEVISION AND I WILL NEVER BE THE WORLD'S MOST INFLUENTIAL ARTIST IF THE SHOW DOES NOT END UP BEFORE.

Ana: OK, KEEP CALM. Let me call a friend.

Ana leaves the place and calls someone

Ana: Roberto Carlos? please, I need your help...

\section{TO BE CONTINUED ...}

Recebido: 29/06/2019

Aceito: 10/07/2019

Publicado: 1/10/2019 